\section{EMPLOYEE WELFARE:DEVELOPING CHANGE STRATEGIES TO ADDRESS EMPATHY BURNOUT IN CARING PROFESSIONS}

\section{Samuel Turner \& Dr Lesley Gill}

\section{INTRODUCTION}

The general health and wellbeing of an organisation's workforce, also referred to as employee welfare, remains a crucial component in organisational and leadership planning. At the level of an individual, welfare is often related to one's level of satisfaction, engagement and dedication. At the organisational level, welfare can be associted with productivity turnove, and enployee relationships. An employee's welfare, particularly in a caring prociated is often sroduct to the em and is often subjety to the en ability to reman enpathic and compscion da be exhausted if not re wo king of experienced by hose working in emotionally demanding roles, such as healthcare professionals, police service an social workers. The common symptoms of empathy burnout include depression, anxiet, absenteeism and letharg At an organisationa level, it is imperative that leadership decisions consider the implications of their profession to the wider wh froce, and so devlop strategies to prevent enpathy burnout. This paper explored the perspectives of employee wellare at a local hospital to develop strategles for change that may assist caring professionals in managing their stress and maintaining levels of empathy. From the exploratory research project, strategies emerged that could be actioned to improve employee welfare across the organisation. These strategies for change included strengthening communication lines to eliminate barriers to support, bolstering the existing employee assistance programme, developing resilience training schemes, and closing the gap between executive leadership and staf. physicians, paramedics, menta health employee, caregiving, counsellors, physiologists, orderly and welfare officers.

Emotional intelligence research remains an area of interest across industries, particularly in human resources management and the healthcare industry (Kurup \& Rishi, 2016). The need for this research originated from the desire of a Health and Safety Manager to understand the current state of employee welfare within their organisation, and explore related benefits available in their workforce. The aim was to understand perspectives of employe welfare at the hospital at the focus of this research, and compare findings between managerial and non-manageria employees. To achieve this aim, a series of semi-structured interviews and quantitative surveys were undertaken with hospital employees including those working in clinical areas, management and administration. Though the sample size of this research was small, the findings revealed a valuable snapshot of employee welfare within the hospital, and and potentially, wider implications.

The questionnaire items that were developed from existing research, assessed three specific themes: employe welfare, empathy burnout, and employee engagement. Initially, the results were indicative of systemic challenges around communication channels and power distance with leadership, further analysis revealed that despite the challenges, employees demonstrated an awareness of others and the ability to identify signs of empathy burnout particularly in clinical areas. This was indicative of strong collegial support across the departments with a genera understanding of the role and its associated risks of burnout. These findings from the survey and semi-structured the needs of the workforce.

At the focus of the research were employees from the emergency department, human resources, occupationa health and safety and clinca wermintration. The pupose of collecting samples from these dipartment widen the scope of research and explore and compare perspectives from clinical, administrative, supportive, managerial and non-managerial employees.

\section{LITERATURE REVIEW}

\section{Employee welfare}

Kurup and Rishi (2016) describe employee welfare as the general health and wellbeing of an organisation's workforce that requires constant focus in organisational decision making and planning. To manage and reduce the risk of burnout and fatigue, Baldschun (2014) suggests welfare-related strategies be implemented at the earliest point of the employee's journey and take a proactive approach to maintaining welfare. Similarly, Robertson and Cooper $(2010)$ discussed a hedonic approach to addressing the psychological welfare of employees. This approach focuses on non-monetary benefits to develop the awareness of mental health and build resilience through positive experiences and strength-based training. As supported by Pawar (2016), improving the psychological welfare of an employee has proven results in the quality of work provided by a 'healthy and happy' employee. In a study exploring the perspectives of childcare workers, Baldschun (20I4) found a strong relationship between the welfare of employees and the resulting welfare outcome for patients. For example, a healthcare professional working overtime without adequate rest breaks is likely to provide poor quality of care to their patient (Baldschun, 2014). Further, Robertson and Cooper (2010) and Pierre and Tremblay (2011), argued that managers are responsible for the welfare of their employees and must do all that is practicable to reduce the risk of psychological difficulties the we fare of their that may result in disengagement, empathy burnout and employee turnover. Taking preventative steps such as Trembly 2011: Bal 2014) It is impors

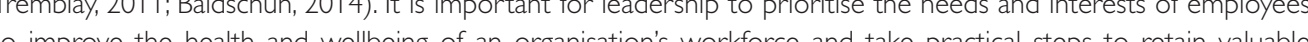
To aldition mental health of a workforce (Robertson and Cooper, 2010).

\section{Empathy burnout}

Empathy burnout is described by Hojat (2009) and Johnson (2013) as a type of emotional stress and exhaustion widely experienced by caring professions where high levels of empathy and emotional intelligence are needed Hofmeyer et al. (2016) describes empathy burnout as "...nurses losing their nurturing ability toward patients, toward colleagues, and toward themselves" (p. 203). Symptoms of empathy burnout may include depression, anxiety, irritability, apathy and physical fatigue (Gill, Schaddelee, Ramsey, Turner \& Naylor, 2018).

Within the context of a hospital setting, factors such as high caseloads, time pressures and unfavourable working conditions may negatively influence an individual's capacity to be compassionate and empathetic towards their patients, and themselves (Kliener \& Wallace, 2017). Employees that work in high-stress environments, particularly with vulnerable clients and/or customers, are predisposed to experiencing multiple types of burnout (Gill, et al., 2018). For managers to reduce the risk of their employees experiencing empathy burnout Kliener and Wallace (2017) suggest engaging employees in self-care and self-awareness education practices to increase their resilience, raise awareness of empathy burnout, and better equip employees to manage their own stress and reduce their 
risk of burnout. Schwerman and Stellmacher (2012) stated improving the support of colleagues and increasing the quality of communication at all levels of an organisation enables employees to share their experiences with others in similar work environments. Furthermore, Thompson (2013) found that providing employees with an opportunity to share with others - particularly those in caring professions - reminds them of why they entered the profession and gives them a renewed sense of value and compassion to carry into their work.

\section{Employee engagement}

An emerging phenomenon and current 'buzzword' in business and psychology literature is Employee Engagement (EE). This is a term that has generated significant interest in the business and human resources community (Zhan Avery, Bergsteiner \& More, 2014; Unal \& Turgut, 2015; lqbal, Shabbir, Zameer, Khan, \& Sandhu, 2017). Zhang et a. (2014) describes EE as, "a heightened emotional and intellectual connection that an employee has for their job. organisation manager, or co-employees that, in turn, influences their ability to apply additional discretionary effort to their work" (p. 27I). Gupta (2015) found that EE could be a tool used to measure the degree to which employees are involved in decision-making and organisational development, instead of completing their assigned roles without the opportunity to influence decisions and planning. Zhang et al. (2014) noted that EE is associated with positively influencing employee turnover satisfaction productivity performance and absenteeism. Similarly, Bakker. Albrecht and Leiter (20I I) found that employees that experience high levels of engagement exhibit attentiveness in their work improved attention to detail, and as a result their quality of work Organisations that adopt a programme to assist planning and implementation of employee engagement strategies see an increase in employee satiffection, trust and dediction (Bakkes et at 2011). According to Gutta (2015) to imp rove Pand dedication (Baker and communication Thus ma bers are likely to experience an incre in

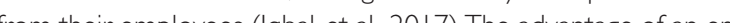

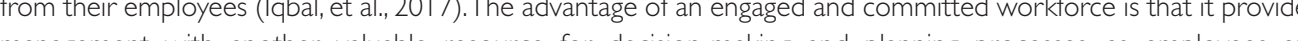

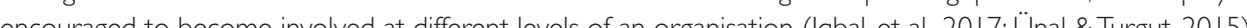

Fully engaged employees who are energetic and enthusiastic are more predisposed to perform Discretionary Service Behaviours (DSB) for their colleagues and organisation (McShane, Olekalns \& Travaglione, 2013; Selander feets emotionally con feets enotionally con to to an organisation and feels the desire to assist customers and colleagues beyond their nomal requirements. In contrast with B haskar and Khera (2014), Salwendar (2015) desch cod DSBs as the positive

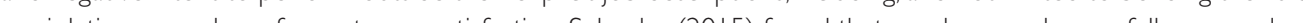

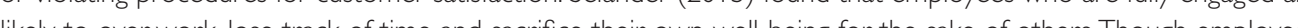
likely to over-work, lose track of time and sacrife their own well-being for the sake of others. Though employees whom are proud and dedicated to their $w$ working overtime becomes the 'norm'.

Though employee engagement can be positive for an organisation, Selander (2015) argues that managers must take practicable steps to ensure a sustainable level of engagement where the concepts of vigour, dedication and absorption are reflected. Managers that invest time and resources in EE see a positive increase in employee satisfaction, dedication and emotional connection to their work. However, there must be a balance between what is sustainable and realistic for employees (vigour, dedication and absorption), and avoid narrow approaches to engagement where the needs of the organisation are above those of employees (Bhaskar \& Khera, 2014).

\section{RESEARCH METHODS}

列 and an electronic survey.

\section{Survey}

The survey questions were formulated from existing research found in the literature and prior research undertaken by the hospital. The questionnaire aimed to assess the themes described in the literature review: employee welfare, empathy burnout and employee engagement. To minimise maturation effects on respondents, a maximum of twenty-five closed-ended questions was allowed, with an expected duration of ten minutes (Mauceri, 2016).

Of the twenty-five questionnaire items included in the survey, five questions measured demographics; four questions measured respondents' knowledge and use of the organisation's welfare-related benefits; five questions related to each literature theme; and one question asked the respondent to write additional comments relating to their perspectives of employee welfare. As described by Mauceri (2016), the respondents were asked to rate their answer on a Likert Scale containing 5 items; strongly disagree; disagree; neutral; agree; and strongly agree. The Likert Scale enabled the researcher to find the average answers among respondents, and draw clear comparisons between data sets (Mauceri, 2016)

At the focus of the survey was non-managerial employees in the emergency department and the clinical records department with a collective sample size of 1 I5. The purpose of using these departments was to gather clinical Of the 115 email s6\%) surveys were returned. Due to concerns of reliability and validity, four responses were removed from the sample $(n=60)$ recorded.

\section{Interview}

As described by Niedzwiecki and Nunnally (2017), the researcher followed a semi-structured format where the questions were prepared before the interview and the interviewee was asked to answer open-ended questions quecific to the research topic The interviews were undertaken to collect data from Human Resources (HR) and specific to he pesthe of employee welfare-related policies and processes.

The interview questions were formulated from existing literature research and prior research undertaken by the organisation. The interview questions aimed to assess the literature themes described in the literature review. To minimise maturation effects on interviewee responses the interview was kept to a maximum of ten questions Of hose ten questions, five reflected employe welfare, two questions measured compassion fatigue two questions measured employee engagementi and one question provided the interviewee the opportunity to comment.

Approximately six $\mathrm{HR}$ and four $\mathrm{OHS}$ personnel were invited to participate in the interviews. The maximum duration of the interviews was 30 minutes and interviewees had the opportunity to opt out or ask any questions before the interview. Of the ten potential interviewees, nine accepted the invitation. 


\section{FINDINGS AND DISCUSSION}

To identify themes in the results, a comparative analysis was undertaken to assess the differences and similarities in responses from survey respondents and interviewees. The predominant themes that emerged from the research findings were self-awareness, communication and leadership. The employee assistance programme is also discussed as it was a common theme among the interviewees.

\section{Self-awareness}

Self-awareness was evident in many survey respondents $(60 \%, \mathrm{n}=36)$ where they said they feel confident in managing their personal work-related stress and fatigue. Miksch, Lindeman and Varghese (2015) defined self-awareness as the degree to which an individual is aware of their own cognitive function and emotional processes. Timmins (2017) described self-awareness as a continuous and evolving process of getting to know who you are" (p. 33). Survey respondents $(64 \%, n=38)$ also demonstrated self-awareness when asked if they are adequately equipped to identify symptoms of stress and/or fatigue, which indicates a perceived awareness of one's cognitive and emotiona processes. Hölzel, Lazar, Gard, Schuman-Olivier,Vago, and Ott (20II) state that individuals with high self-awareness are likely to identify emotional stress in others. It is reassuring that over two thirds of the survey respondents $(70 \%$ $n=42$ ) said they felt confident in identifying emotional stress in others. Just under half of the survey respondents $(45 \%, n=27)$ said they would talk to someone when they are struggling with their workload. While respondents showed self-awareness of their stress, they said they were much less likely to ask for help, or recognise their hig workload until they were stressed, and so their ability to identify when they are struggling may be limited. Griffith and West $(2013)$ noted that self-aware individuals are likely to approach someone when they are struggling with difficult situations or tasks. However, Hofmeyer et al. (2016) stated that healthcare employees are likely to care for others, regardless of the potential personal cost to themselves According to Wood et al (2017) and Engle et (2017) healthcare employes are predisposed to experience symptoms of compassion fatigue as they operate in a challenging and complex environment where their primary focus is patient care.

Self-awareness is noted by Wood et al. (2017) as one of the primary traits of a resilient person, as it requires the person to have the ability to focus inward and acknowledge one's emotions. Interestingly, the survey respondents' answers to self-awareness seemed to contradict their understanding of their own resilience. From another perspective, survey respondents' inability to enforce positive change or working conditions might indicate sefawareness and resilience in managing long-term stress. Hofmeyer et al (2016) argued that leaders' responselly of their employees is particulaty important in healthere industies where symptoms of compassion fitige are prevalent.

Survey respondents that demonstrated high levels of self-awareness of others $(88 \%, n=53)$, and the willingness to help their colleagues $(88 \%, n=53)$, suggests high collegiality or a mutual understanding of the work environment and identified ways to reduce stress. According to Griffith and West (2013), self-aware individuals are likely to show compassion and empathy towards their colleagues, as they become more adept at identifying emotional stress in others. Conversely, Engle, Peterson, McMinn and Taylor-Kemp (2017) found employees that were low in selfawareness experience poorer relationships with their colleagues. If an individual does not understand the emotiona stress of others on a cognitive level, they lack the aptitude to identify when a colleague may be struggling. Additionally Timmins (201I) and Kemerer and Cwiekala-Lewis (2017) argued that self-awareness is vital for developing one's communication skills and interpersonal relationships.

\section{Communication and leadership}

Of the 60 survey respondents, $46 \%(n=28)$ said it was difficult to speak up if they perceived a problem; althoug $35 \%(n=21)$ sald they would speak up. This may indicate that employees are aware of their situation, but there are barriers in communication, or they lack the power to change their circumstances. Timmins (20II) and Kang and Sung (2017) argue that effective communication is at the forefront of successful relationships in an organisation, where trust, transparency and appropriate behaviours that unite employees. According to Zheng. Molineux Mirshekary and Scarparo (2015) good communication is closely linked with employee welfare as employees are likely to approach their colleagues or leaders with ideas or concerns.

As described by Kang and Sung (2017), and Kemerer and Cwiekala-Lewis (2017), leaders are responsible for ensuring clear lines of communication throughout an organisation, and the resources to manage emotional stress and fatigue as captured in this interviewee's comment:

The employer loses credibility when they are not transparent. Executive Leader ship Team (ETL) are so far removed from employees that they aren't trusted anymore You must earn the trust of the employees. Leaders must demonstrate [organisational] values and behaviours.

In relation to the survey findings, $50 \%$ of survey respondents $(n=60)$ said they do not feel appreciated for the contribution they make. One reason for this may be that employees are receiving limited feedback and are unsure of their place or performance in the organisation. According to Zheng et al. (2015), open and honest feedback enables employees to learn from their mistakes and thrive in their respective industries. Half of the interview participants said they felt underappreciated due to the lack of clear communication or feedback from their leaders. One managerial perspective from the interviews suggested the distance between leadership and employees was a contributing factor to the gap in communication:

Loyalty and respect towards staff is so important. Distance between ELT and staff is huge. ELT should show support - show that they are part of the staff. Approachability visibility and connectivity. Ensure employees are listened to and heard.

Employees said they were aware of their colleagues and felt confident in identifying stress in others. However, the results indicated potential challenges to communication where a mixed response $(52 \%, n=60)$ felt comfortable reporting concerns about others' safety, while only $53 \%$ (of that $52 \%, n=60$ ) said they would report concerns about themselves. One manager said in an interview.

Communication gets lost. Some areas are good, some are not so good. Informa-

Communication gets lost. Some areas are good, some are not so good. Information is not filtered down from managers to employees. Employees might get a message to managers, but it may get blocked

The link between communication and leadership was established in the survey, where less than half of respondents $(43 \%, n=60)$ said that leaders communicate well, and that employees generally know what is going on. If there is fault in communication, Aas et al. (2008) noted that monitoring and implementation remains the responsibility of leadership (Zhang, et al., 2014;Timmins, 2017). When employees are engaged in the process and given opportunity to communicate openly with leaders, positive increases in welfare, turnover and performance are observed (Zheng, et al., 2015). Many survey respondents $(67 \%, n=60)$ said they felt committed to their work when management encouraged them to contribute to decision-making as this next interview comment suggests:

Internal emails and intranet - good for me when I'm at my computer all day Not everyone gets a chance to view these emalls. I don't think the communication gets there. Nurses are too busy to see messages, posters and training.TVscreens are great, but most information is through emails and Pulse.

Not everyone sees information around the hospital. Not every nurse or doctor gets to see this information as they are so busy and short staffed. According to Celma, Martinez-Garcia and Raya (2018), socially responsible leaders take initiative when implementing communication models, ensuring it addresses the needs of all employees. Models 
that are open, versatile, and flexible positively correlated to improving quality of work and employee welfare, as employees felt trusted and valued (Mathews \& Crocker, 2016: Celma, et al, 2018).

\section{Employee assistance programmes}

The interview findings appeared to be concerned around the Employee Assistance Programme (EAP) currently avallable to employees, and that staff need to know about it. Kurup and Rishi (2016) argued a strong presence of employee welfare activities and benefits increases trust and satisfaction among employees. Additionally, Ganes (2017) noted that a flow-on affect from such welfare benefits can be observed through positive increases in performance, engagement and development. According to Shapiro, Carlson, Astin and Freedman (2005) communication and transparency are key to building trust in the employee-employer relationship. In the survey $31 \%(n=19)$ of respondents said they were aware of EAP, and of those respondents only 17\% $(n=10)$ had used the service. This was further captured in the interviews:

Is underutilised. Not well communicated. There is a general lack of awareness. am obliged to refer employees, though I don't think EAP is effective. I don't believe in the service they provide as there is no way to follow up, no reporting whatsoever.

Employees are likely to participate in welfare-related activities if they are made aware of what they are and given an opportunity to contribute to the selection of appropriate activities that addresses their needs (Mathews \& Crocker 2016). Mathews and Crocker (2016) suggest encouraging employee buy-in where they engage at the planning level, and work together to develop activities best suit their needs. As described by one interviewee

We need more initiatives. Communicated well, and ensure awareness is high.

Different things will improve culture in the organisation, and people would hopefully buy into it.

Shapiro et al. (2005) suggest that leaders need to encourage engagement and buy-in from employees, enabling leaders to demonstrate willingness and transparency to follow through with employee requests. As described by Réka and Borza (2012), follow up is a crucial component in effective communication, particularly across diverse organisations. Additionally, Minter (2010) states that seeking feedback is key in improving processes in an organisation. A lack of reporting and followup was reported by an interviewee

EAP has no current measures, so not sure of its effectiveness. Reports could be useful to see the number of employees that go through.

Although the service provided by EAP is confidential, there is a general understanding by interviewees that there needs to be a follow-up process where managers may assist their employees further. For managers to ensure the effectiveness and availability of resources, Engle et al. (2017) argues that a 'next-step' of seeking feedback is necessary to match support systems with employee needs. As one interviewee stated:

Often, we don't know anything. It is a confidential service. Lack of reporting

merics (EAP) means we don't know how else to support them if we don't know.

Employees don't necessarily tell us, so how can we assist them further? There is

no current followup process.

As described by Ganesh (2017), employees are vital to the organisation's success, and must be nurtured and supported well. Programmes such as EAP, though valuable to employees, must be assessed, evaluated and communicated effectivel

\section{CONCLUSION}

The research methods used to gather data and achieve an understanding of the perspectives of employee welfare included a survey distributed to non-mana included a

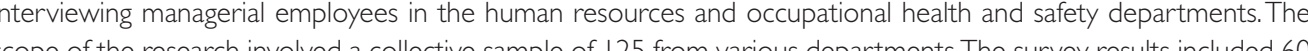
(a) responses. Following an analysis, three predominant themes were identifed as self-awareness, communication and

The survey revealed a positive level of self-awareness in relation to the workload or seeing emotional stress in their colleagues However only hal of respondents sid they would communicate if they perceived a problem, ind colleagues. Howerer only haf of respondents said they would communicater in

The interviewees revealed similar perspectives in relation to communication, where the current communication models are not sufficient to address the needs of a diverse organisation. Leadership may be contributing to this dilemma as the perceived distance between managers and employees discourages people to come fonward The there appears to be inadequate follow-up processes or reporting metrics.

Given the link between the resulting themes from the results, the change strategies identified in this research are: (1) Identify and implement ways of increasing employee engagement: (2) Create opportunities for manasers and staff to communicate effectively to identify employee needs; (3) Evaluate the EAP programme to noced and staff to communicate effectively to identify employee needs; (3) Evaluate the EAP programme to increase its who experience stress and empathy burnout in the course of their work will dramatically increase emplopee welfare in caring professions.

An opportunity for future research would be to extend the scope of the research to multiple departments and include perspectives from senior and executive leadership, particularly to understand perspectives of employee welfare at a strategic level. 
Samuel Turner is a recent Human Resources Management graduate working in the People and Culture team at Otago Polytechnic (OP). Sam's research focus is in Emotional Intelligence and Contemporary HR, specifically areas of personal and professional development. He also holds an active interest in Research Ethics on the OP Research committee, and remaining connected with business degree students.

Dr Lesley Gill is a Principal Lecturer at Otago Polytechnic, teaching Leadership, Human Resource Management and Strategic Management Her PhD focused on Emotional Intelligence training design. Lesley runs workshops in resilience, self-awareness, and empathy She has hosted four El symposiums since 2012. Lesley publishes her research in qualty internstionat and nationa peerreviewed jurnals publications and conferences and co-authored Organisations \& Management textbook

\section{REFERENCES}

Aas, R.W. Ellingsen, K. L., Lindøe, P., \& Möller, A. (2008). Leadership qualities in the return to work process:A content analysis. Joumal of Occupational Rehabilitation, 18(4), 335-346.

Anaza, N. A., Nowlin, E. L., \& Wu, G.J. (2016). Staying engaged on the job. European Journal of Marketing, 50(7), $1470-1492$.

Bakker, A. B., Albrecht, S. L., \& Leiter, M. P. (20I I). Key questions regarding work engagement. European Journal of Work and Organisational Psychology, 20(I), 4-28.

Baldschun, A. (2014). The six dimensions of child welfare employees' occupational well-being. Nordic Journal of Working Life Studies, 4(4), 69-87.

Bhaskar, S., \& Khera, S., N. (2014). Antecedents of discretionary risky-service behaviour: An exploratory study. The Intemation Joumal of Bank Marketing, 32(6), 477-493.

Celma, D. Martinez-Garcia, E., \& Raya, I. M. (2018). Socially responsible HR practices and their effects on employees' wellbein Empirical evidence from Catalonia, Spain. European Research on Management and Business Economics, 24(2), 82-89.

Engle, N.W., Peterson, M., McMinn, M., \& Taylor-Kemp, N. (2017). Stressors and resources of psychologists: How are helpers bein helped? North American Journal of Psychology, 19(1), $123-137$.

employee satisfaction at Mangalore refinery and petrochemicas limited. Drishtikon: A Management Journal, 8(I), 30-48.

, L., Schaddelee, M., Ramsey, P, Turner, S. \& Naylor, T. (2018). When empathy works: Towards finding effective ways of sustaining empathy flow. Asia-Pacific Management and Business Application, 6(3), II5-136.

Griffith, ... \& West, C. (2OI3). Master resilience training and its relationship to individual well-being and stress buffering among army National Guard soldiers. The Journal of Behavioural Health Services \& Research, 40(2), 140-55.

Gupta, M. (2015). A study on employee's perception towards employee engagement. Globsyn Management Journal, 9(I), 45-5!

Hofmeyer, A., Toffoli, L..Vernon, R., Taylor, R., Fontaine, D., Klopper, H. C., \& Siedine, K. C. (2016). Teaching the practice of compassion to nursing students within an online learning environment: A qualitative study protocol. Contemporary Issues in Education Research, 9(4), 201-222.

Hö̈zel, B. K., Lazar, S. W., Gard, T., Schuman-Olivier, Z., Vago, D. R. \& Ott. U. (20I I). How does mindfulness meditation work Proposing mechanisms of action from a conceptual and neural perspective. Perspectives on Psychological Science, 6(6), 537-559. Hojat, M. (2009). Ten approaches for enhancing empathy in health and human services cultures. Journal of Health and Human Services Administration. 31 ( 4$), 412-450$.

Huong, L., Zheng, C., \& Fujimoto, Y. (2016). Inclusion, organisational justice and employee well-being. Intermational Joumal of

Iqbal, J., Shabbir, M. S., Zameer, H., Khan, I. A., \& Sandhu, M. A. (2017). Antecedents and consequences of employee engagement idence from copporate setor of Pakistan Paradigms, II (I), 78-86

James, L. \& Mathew, L. (20 I2). Employee retention strategies: IT industry. SCMS Joumal of Indian Management, 9(3), 79-87.

Johnson, D. (2013). Empathy can be exhausting. ISHN. 47(9), 10-11.
Kang D. U., Gun, I.Y. \& Lee, S. (2016). Disentangling the effects of the employee benefits on employee productivity. Joumal of Applied Business Research. 32(5), 1447-1458.

Kang, M., \& Sung, M. (2017). How symmetrical employee communication leads to employee engagement and positive employee (I)

Kemerer, D., \& Cwiekala-Lewis, K. (2017). Leading by walking around in long-term care and transitional care facilities. Nursing Management, 24(3), 25-29.

Kleiner, S. \& Wallace.J. E. (2017). Oncologist burnout and compassion fatigue: Investigating time pressure at work as a predictor and the mediating role of work-family conflict. BMC Heath Senvices Research, 17(I), I-8.

Kurup, P., \& Rishi, P. (2016). A study of employee welfare and performance appraisal practices in relation to organisational climate in public and private sector insurance companies of central India. Joumal of Organisation and Human Behaviour, 5(3), 14-20. Mathews, B.W. \& Crocker. T. (2016). Defining buy-in: Introducing the buy-in continuum. Organization Development Joumal, 34(2). $81-96$.

. 1231.

M.Shane, S. Olekalns, M. \& Travaglione, A. (2013). Organisational behaviour: Emerging knowledge, global insights (4th Ed.). North Ryde, Australia: McGraw Hill.

Miksch, D. Lindeman, M. I. H., \& Varghese, L. (2015). Minding the mechanisms: A discussion of how mindfulness leads to positive outcomes at work. Industrial and Organizational Psychology, 8(4), 620-629.

Minter, R. L. (2010). Organizational communication audits: Assessing core communication competencies within the organization. International Juurnal of Management \& Information Systems, I4(5), 107- I 18.

Niedzwiecki, S., \& Nunnally, D. (2017). Mixed-methods research in the study of welfare states. PS, Political Science \& Politics, 50(4), 1028-1031.

Pawar, B. S. (2016).Workplace spirituality and employee well-being: An empirical examination. Employee Relations, 38(6), $975-994$. Pierre, X., \& Tremblay D. (201 I). Levels of involvement and retention of agents in call centres: Improving well-being of employees for better socioeconomic performance. Journal of Management Policy and Practice, |2(5), 53-7|.

Rajmohan,T. (2015). Interpersonal competencies of executives in service organizations. Parikalpana:K IT Journal of Management, I I (2), $75-94$.

Réka, K., \& Borza, A. (2012). Internal and external communication within cultural organizations. Management \& Marketing, 7(4). $613-630$

Robertson, I. T., \& Cooper, C. L. (2010). Full engagement: The integration of employee engagement and psychological wellbeing. Leadership \& Organization Development Journal, 31 (4), 324-336.

Selander, K. (2015). Work engagement in the third sector. Voluntas, 26(4), 1391 - | 41 .

schwerman, N., \& Stellmacher,J. (2012). A holistic approach to supporting staff in a paediatric hospital setting. Workplace Health \& Safety, 60(9), 385-90.

Shapiro, S., Carlson, E. L., Astin, A.J., Freedman, B. (2005). Mechanisms of mindfulness. Journal of Clinical Psychology, 62 (3), 373-386. avares, R. d. S. C. R., \& Kamimura, Q.P. (2014). Productivity and presenteeism - A question of sleeping well. Independent Journal of Management \& Production, $5(2), 417-437$

Tvares, S., Seers, K, Tutton, E., \& Reeve, J. (2017). Enabling the flow of compassionate care: A grounded theory study. BMC Health Services Research, I7(1), I-12.

IImmins, F. (201 I). Managers' duty to maintain good workplace communications skills. Nursing Management (through 2013), 18(3),

Thompson,A. (2013). How Schwartz rounds can be used to combat compassion fatigue. Nursing Management (through 2013), 20(4),

Unnal, Z. M., \& Turgut, T. (2015). The buzzword: Employee engagement. Does person-organisation fit contribute to employee engagement? Iranian Journal of Management Studies, 8(2), 157-179.

Wood, A. E., Prins, A., Bush, N. E., Hsia, I. F., Bourn, L. E., Earley, M. D., Ruzek, J. (2017). Redutton of bumout in mental health care Conmity Mental Health Journal, 53(4), 452-459.

Zhang, T., Avery, G., C., Bergsteiner, H., \& More, E. (2014). Do follower characteristics moderate leadership and employee engagement? Jurnal of $G$ bod Responsibility, 5(2). 269-288. Zheng, C.. Molineux, J., Mirshekary, S. \& \& Scarparo, S. (2015). Developing individual and organisational work-life balance strategies to
improve employee health and wellbeing. Employee Relations, 37(3), 354-379. 